\section{Textile Design and Colour}

Elementary Weaves and Figured Fabrics. By William Watson. Fifth edition. Pp. xii+513. (London, New York and Toronto : Longmans, Green and Co., Ltd., 1946.) 25s. net.

7 HE author, in this edition of his book, has revised the earlier editions and added further chapters bringing his subject-matter up to date. The volume is, in consequence, more interesting and comprehensive and, because of its wider scope, more likely to have a general appeal.

In the earlier chapters, a detailed and well-illustrated description is given of all the simpler fundamental weaves requiring one warp and one weft, which makes this portion of the book particularly suitable for the young student or for those wishing to revise their knowledge of fabric structure. Herein, one finds all the structures clearly defined from plain weave, twills, satins, sateens, to bedford cords and piqués.

The second portion of the book, which describes the light and pigment theories of colour and their simple application to woven textiles, is sound, as are the chapters dealing with the simpler jacquards and the figured fabrics woven thereon. The author presents, in a lucid manner, the method by which jacquard designs are produced from the sketch, and developed through point paper drafting to the woven fabric.

But it is the latter part of the book which the more experienced reader will find valuable. To anyone connected with the textile industry, the glossaries of yarns, weaves and fabrics are most useful as sources of reference. The chapter on the manufacture of rayon, outlining as it does the processes for producing the different types, and the section on recent developments in fibres and yarns are particularly interesting, especially when dealing with the characteristics and definitions of the new synthetic yarns. The subject of cloth firmness, with the necessary calculations for finding the ideal cloth particulars, or any required changes either in sett or counts of yarn, will be found useful to both student and manufacturer alike.

In fact, this volume is a good, sound text-book and is recommended to those requiring a thorough knowledge of the simpler weaves and of the yarns necessary for building up their structures.

\section{A. M. Latham}

\section{Differential and Integral Calculus}

By Prof. Ross R. Middlemiss. Second edition. Pp. viii + 497. (New York and London: McGraw-Hill Book Co. Inc., 1946.) 16s. 6d.

THE first edition of this very useful book was briefly reviewed in Nature of July 19, 1941. In this new edition, the general plan has been retained and such modifications made in the text as experience has rendered necessary. These changes have involved the rewriting of many sections and several entire chapters. A serious attempt has been made to improve the rigour without adding to the difficulty of the text. For example, the treatment of partial derivatives has been practically recast in order to place emphasis on physical rather than purely geometrical aspects, while the chapter on multiple integrals has been revised and expanded to include spherical as well as cylindrical co-ordinates.

A commendable change in the sections devoted to the applications of the definite integral is the sub- stitution of Duhamel's principle by simpler and, in some cases, by more valid methods. A drastic revision of the chapter on infinite series has been made, which now includes a useful theorem for estimating the comparative value of the remainder after $k$ terms.

Finally, most of the problems in the original edition have been replaced and the total number increased. Curiously, answers are only provided to those exercises which bear odd numbers. As in the earlier edition, the text is clearly printed and excellently illustrated by many well-drawn figures.

Undoubtedly, the changes made by the author tend to improve the book, and no reader should have any difficulty in gaining a thorough understanding of the fundamental principles of the calculus.

\section{Acoustics for Architects}

By Dr.E.G. Richardson. Pp. 90. (London: Edward Arnold and Co., 1946.) 5s. net.

A $\mathrm{S}$ the title implies, this small book is specially written for the 'general practitioner' in architecture, who merely requires, according to the author, a statement of the fundamental acoustic principles, and help in applying them in practice. It is not intended for the physicist, who would, of course, find it far from satisfying.

In the first chapter, the author gives just sufficient information concerning the characteristics of sound to enable him to make the rest of the book fully intelligible to the reader, and he does this very well. Further, he emphasizes the importance to the architect of securing uniform acoustic conditions in a hall over the important range of frequency which lies between 100 and 5,000 vibrations per second.

A very useful second chapter is devoted to a historical survey of the study of the acoustics of buildings, to help the student to understand the problems which arise in applying the laws of sound to architecture. From this point the author develops his theme in a logical and clear way, and the last chapter gives a résumé of the principles of acousties in the form of suggestions for planning various types of auditorium for the best conditions of listening.

The book, which is produced under war economy conditions, is well written, and what diagrams are included are straightforward and understandable.

\section{Vie et transmutations des atomes}

Par Jean Thibaud. (Scionces d'aujourd'hui.) Deuxieme édition revisée. Pp. $290+24$ plates. (Paris: Albin Michel, 1942.) 86 francs.

CINCE 1942, when this revised edition of an older $\$$ book of 1937 appeared, relatively little has been published on nuclear physics, except in connexion with fission. This exceedingly lucid account of the subject, which has been received recently, probably remains one of the best of the few available texts of its kind. Emphasis is primarily on the experimental side, but the references to nuclear theory, and to fundamental matters of a more general character, are apt and suggestive. The plates constitute a most attractive feature. There are twenty-four of them, each beautifully printed on a separate page. A number are copied from other publications, but some appear to be original. Altogether they provide, among other things, a vivid record of the appearance of a nuclear physics laboratory and of the apparatus used in it, which is possibly of more than passing interest. 